\title{
PECULIARITIES OF PERFECTION OF TRAINING PROCESS OF THE QUALIFIED BODYBUILDER IN THE COMPETITIVE PERIOD
}

\author{
Dzhym V. Yu.
}

Kharkov State Academy of Physical Culture

\begin{abstract}
Annotation. Purpose: study methods of improving the training process of skilled bodybuilders in the competitive period. Material: The study involved 18 athletes aged 18-25 years old. The experiment was conducted for 8 weeks. Used two variants of training techniques: large percentage weights; with smooth dynamics with emphasis on static load muscles. Efficacy was evaluated using the preparation method of expert evaluations. The method involved the use of information on the implementation of directives coach dynamics of power and endurance performance, subjective indicators (health, mood, desire to train). Results: comparative characteristic of the most commonly used methods of training process in bodybuilding. Developed and justified best practices, depending on the initial form of the athlete at the beginning of the competition period of training. Shows the dependence of changes in body weight of the athlete training. Conclusions: the proposed best practices, depending on the microcycle training in the competitive period (precompetitive and competitive mesocycles).
\end{abstract}

Keywords: training, bodybuilding, qualified, optimal, method, microcycle.

\section{Introduction}

Since $90-$ s, in Ukraine new for the country kinds of sports have been becoming more and more popular. In weight lifting they were, first of all, power-lifting and bodybuilding. Considering the fact that domestic theoretical and practical trainings base for such kinds of sports is only on stage of creation, the topic of this article is rather urgent for domestic sports.

One of most important problems of bodybuilders' training for competitions in Ukraine is adaptation of foreign classic methodic to domestic reality and, thus to achievement of high results.

Training system of qualified body builders is based on rationally built training process in combination with diet as factor, ensuring required material for decreasing of fat layer and growing of muscular mass.

That is why there was worked out and scientifically grounded methodic of training process of qualified bodybuilders in competition period of year training cycle $[1 ; 2]$.

In domestic sports there is a little of scientifically grounded training methodic for qualified bodybuilders in preparatory period of special-training stage. Thus, coaches and sportsmen shall acquire practical experience by the method of trial and error $[6 ; 9]$.

In bodybuilding competition process lasts 8 weeks. In this period qualified sportsmen of different age groups and categories try as much as possible to reduce under-skin fat layer and water with the help of trainings with optimal weights. At the end of every micro-cycle form of sportsman is estimated by coaches and anthropometric data are measured, corrections in training process and plan of diet are made $[3 ; 15-18]$.

This problem was dealt with by such outstanding domestic specialists in physical culture as V.M. Platonov, L.S. Dvorkin, A.I. Stetsenko, B.I. Sheyko, V.G. Oleshko, A.I. Kamayev, D.A. Beskorovayniy, V.V. Usichenko [4-10]. Their researches based on experience of such foreign specialists as Joe Wider, Ben Wider, E. Connors, T. Kimber, M. Mc Kormic [12-14].

The present scientific research has been fulfilled as per topic of combined plan of scientific-research works in sphere of physical culture and sports for на 2011-2015. Topic 3.7 "Methodological and organizational methodic principles of determination of individual norm of human physical condition" (state registration No. 0111U000192).

\section{Purpose, tasks of the work, material and methods}

The purpose of the research: To give foundation to methodic of improvement of qualified bodybuilders' training process in competition period.

The methods of the research: Theoretical method and generalization of literature, pedagogic observation, pedagogic experiment, method of mathematical statistics.

Materials of the research: members of combined team of Kharkovska region participated in the experiment. They were 18 bodybuilder: 4 masters of sport, 14 - candidate masters of sports of 18-25 years old; mean body mass was $85 \pm 2-100 \pm 2 \mathrm{~kg}$. The participants were distributed by sport qualification into two groups": experimental (EG) and control group (CG). Control group sportsmen trained 5 times a week; experimental group trained 5-6 times a week.

\section{Results of the research}

Usage of training process of qualified bodybuilders conditioned application of two training methodic, which differed by load and scope of trainings exercises, rest periods and other components. Evaluation was conducted with the help of training diaries, in which quantity and scope of training work was noted.

Training effectiveness was evaluated with method of experts' evaluation, which envisaged application of information about fulfillment of coach's instructions, dynamic of power indicators and endurance as well as subjective qualities (self-feeling, mood, wish to train and so on).

\footnotetext{
(c) Dzhym V. Yu.

2015 http://dx.doi.org/10.15561/20755279.2015.0102
} 
Control group sportsmen trained during 8 weeks with great percentage loads; experimental group sportsmen trained with smooth dynamic with static exercises prevailing (see table 1,2) Before experiment we fulfilled testing measuring of sportsmen's masses, anthropological measurements for determination of better results in indicators' increment. For weighing, we used mass analyze (scales TANITA BC-545, made in Japan) and centimeter measuring tape (see table 3, 4).

Distinction of preparatory period from competition one is in more smooth transition from one training microcycle to other, as well as in increasing of quantity of repetitions and trials for better separation and definitions of muscles (see table 1). Increasing of trainings' quantity, shortening of breaks between trainings days is very important in preparation at this stage. Also, as it can be seen in table 1, intensity is important; time of exercises' fulfillment significantly reduced both in positive and negative phases and pauses between repetitions reduced - in preparation cycle up to $0.5 \mathrm{sec}$. and in competition micro-cycle there was no rest between repetitions at all.

Specificity of this stage is also little percent application of small weights, which was in first pre-competition meso-cycle in EG - 50\%, and in CG 60 - 80\%, in second competition meso-cycle - 70 - 30\% in EG and $80-70 \%$ in $\mathrm{CG}$, thus in EG greater attention was paid to work with muscles, but not to gaining mass that was most important at this stage.

Table 1

Content of training program depending on mass of load in competition period of qualified bodybuilders (experimental and control groups)

\begin{tabular}{|c|c|c|c|c|}
\hline \multirow{3}{*}{$\begin{array}{l}\text { Indicators of training loads and } \\
\text { classification of muscular groups }\end{array}$} & \multicolumn{4}{|c|}{ Meso-cycles } \\
\hline & \multicolumn{2}{|c|}{ Pre-competition } & \multicolumn{2}{|c|}{ Competition } \\
\hline & CG & EG & CG & EG \\
\hline Range of load in percent from maximum & $60-80$ & $30-60$ & $80-70$ & $70-30$ \\
\hline Quantity of training days & 5 & 6 & 6 & 6 \\
\hline Quantity of repetitions & $10-12$ & $12-18$ & $12-15$ & $15-25$ \\
\hline Quantity of trials & $5-6$ & $5-6$ & $5-6$ & $6-8$ \\
\hline \multicolumn{5}{|c|}{ Time of exercise's fulfillment, sec. } \\
\hline $\begin{array}{l}\text { POSITIVE PHASE (MOVEMENT } \\
\text { UPWARD) }\end{array}$ & 1 & 0,5 & 1 & 0,5 \\
\hline Negative phase (movement downward) & 1,2 & 0,5 & 1 & 0,5 \\
\hline Pauses between repetitions, sec. & 0,8 & & 0,5 & - \\
\hline \multicolumn{5}{|c|}{ Rest between trials, min. } \\
\hline In basic exercises & $2-2,5$ & $1-1,2$ & 1,5 & 1 \\
\hline In shaping exercises & 1,5 & 50 & 1 & $30-50$ \\
\hline \multicolumn{5}{|c|}{ Rest time between loading of muscular groups (days) } \\
\hline Hips & 5 & 3 & 4 & 3 \\
\hline Back & 5 & $3-5$ & 4 & $3-5$ \\
\hline Breast & 3 & 4 & 3 & 4 \\
\hline Deltoid muscle & 4 & 5 & 4 & 5 \\
\hline Biceps muscle & 2 & 3 & 2 & 3 \\
\hline TRICEPS MUSCLE & 3 & 4 & 3 & 4 \\
\hline Forearm & 6 & 5 & 6 & 5 \\
\hline Triceps of shin & 6 & 3 & 6 & 3 \\
\hline Oblique and direct abdominal muscles & 3 & 1 & 3 & 1 \\
\hline Neck & 0 & 2 & 0 & 2 \\
\hline
\end{tabular}

The data, presented in table 2, witness that experimental group sportsmen trained with moderate weights comparing with maximal; control group trained with little quantity of repetitions but with heavy weights that is not recommended in pre-competition period, because in this period sportsmen, preparing for competitions, reduce quantity of carbon hydrates. For example, in competition period great attention is paid to muscles of hip and shin - quantity of weight bar's lifting (QWBL) is 1.797 in EG per two micro-cycles, in CG - 1.566 mainly at the account of muscles of arms, breast and back, which are practically same (650- 732 lifting of 62.500-96.400kg weight). But in this period main role is played by shaping exercises, which were different by QWBL and by calculated kilograms; that is why maximally great number of weight bar lifting was at the account of oblique and direct abdominal muscles and was in EG 9.220 QWBL and in CG 8.850 QWBL. Total scope of QWBL in basic exercises was in EG 5.254 and in CG 4.457, while in shaping exercises in EG it was 17.900 and in CG - 16.451 QWBL. Thus, CG used more powerful program of training and little quantity of QWBL with big weights. EG used more static program of training and used higher quantity of QWBL that is why scope of kilograms was higher. 
Table 2

Total scope of training work, fulfilled by qualified bodybuilders of control and experimental groups in competition period

\begin{tabular}{|l|l|l|l|l|}
\hline \multirow{2}{*}{ Group s of muscles } & \multicolumn{1}{c}{ Scope of QWBL } & \multicolumn{2}{l|}{ Scope, thousands of kg. } \\
\cline { 2 - 5 } & CG & EG & CG & EG \\
\hline \multicolumn{2}{|c|}{ Basic exercise for: } \\
\hline Muscles of upper girdle & 550.0 & 650.0 & 59.200 & 62.500 \\
\hline Muscles of arms & 780.0 & 900.0 & 76.550 & 85.660 \\
\hline Muscles of breast & 582.0 & 732.0 & 88.250 & 96.400 \\
\hline Muscles of back & 979.0 & 1.175 & 166.100 & 182.090 \\
\hline Muscles of hips and shins & 1.566 & 1.797 & 240.562 & 305.695 \\
\hline Total & 4.457 & 5.254 & 630.662 & 732.345 \\
\hline \multicolumn{5}{|l|}{} \\
\hline Muscles of upper girdle & 1.550 & 1.632 & 110.340 & 139.520 \\
\hline Muscles of arms & 820.0 & 965.0 & 58.250 & 65.380 \\
\hline Muscles of breast & 520.0 & 630.0 & 63.670 & 65.380 \\
\hline Muscles of back & 1.035 & 1.368 & 105.350 & 118.080 \\
\hline Muscles of hips and shins & 3.676 & 4.105 & 505.250 & 537.740 \\
\hline Oblique and direct abdominal muscles & 8.850 & 9.220 & - & - \\
\hline Total & 16.451 & 17.900 & 842.860 & 926.100 \\
\hline
\end{tabular}

Notes: QWBL - quantity of lifting of weight bar

Total scope of calculated kilograms in basic exercises is 732.345 in EG and 630.662 in CG; in shaping exercises total scope is $926.100 \mathrm{~kg}$ in EG and 842.860 in CG. We can make general conclusion that experimental group sportsmen trained at this stage with moderate scope of kilograms and paid more attention to abdominal muscles and muscles of legs as far as after preparatory period (28 micro-cycles) there was significant increment of subcutaneous fat layer on abdomen and hips. In their turn, CG sportsmen paid more attention to basic exercises and power indicators than to shaping exercises.

Before experiment we fulfilled anthropological measurements. As we can see in table 3, variation coefficients of all main anthropological indicators, separately for control and experimental groups, practically did not exceed general initial level.

Anthropometrical examination was fulfilled before beginning and at the end of competition period,(see tables $3,4)$.

Table 3

Mean anthropological indicators of qualified bodybuilders of control and experimental groups at the beginning of competition period $\left(n_{1}=n_{2}=9\right)$

\begin{tabular}{|l|c|c|c|c|c|c|}
\hline \multirow{2}{*}{ Indicator } & \multicolumn{2}{|c|}{ CG } & EG & \multirow{2}{*}{$P$} \\
\cline { 2 - 7 } & $\bar{X}_{1} \pm m_{1}$ & $V, \%$ & $\bar{X}_{2} \pm m_{2}$ & $V, \%$ & & \\
\hline Body mass, kg & $94.17 \pm 3.74$ & 11.91 & $94.00 \pm 4.17$ & 13.30 & 0.02 & $>0.05$ \\
\hline Circumference of neck, cm & $42.50 \pm 1.36$ & 9.62 & $42.78 \pm 1.29$ & 9.03 & 0.12 & $>0.05$ \\
\hline Circumference of breast (inhale), cm & $113.83 \pm 1.88$ & 4.95 & $117.88 \pm 2.60$ & 6.62 & 1.03 & $>0.05$ \\
\hline Circumference of breast (exhale), cm & $105.33 \pm 1.91$ & 5.43 & $107.22 \pm 2.26$ & 6.32 & 0.52 & $>0.05$ \\
\hline Circumference of biceps, cm & $43.00 \pm 1.91$ & 13.32 & $44.45 \pm 1.59$ & 10.72 & 0.48 & $>0.05$ \\
\hline Circumference of waist, cm & $80.33 \pm 2.34$ & 8.76 & $81.95 \pm 2.52$ & 9.22 & 0.38 & $>0.05$ \\
\hline Circumference of hip, cm & $79.00 \pm 1.74$ & 6.60 & $79.72 \pm 1.84$ & 6.93 & 0.23 & $>0.05$ \\
\hline Circumference of shin, cm & $40.33 \pm 1.31$ & 9.75 & $41.12 \pm 1.41$ & 10.32 & 0.33 & $>0.05$ \\
\hline Circumference of forearm, cm & $37.33 \pm 1.32$ & 10.64 & $39.17 \pm 1.85$ & 14.21 & 0.66 & $>0.05$ \\
\hline Length of body, cm & $168.00 \pm 1.40$ & 2.50 & $170.50 \pm 2.25$ & 3.96 & 0.77 & $>0.05$ \\
\hline Length of torso, cm & $77.83 \pm 0.65$ & 2.49 & $78.00 \pm 0.63$ & 2.43 & 0.15 & $>0.05$ \\
\hline Length of lower limb, cm & $90.17 \pm 0.88$ & 2.93 & $90.33 \pm 0.91$ & 3.02 & 0.11 & $>0.05$ \\
\hline Length of upper limb, cm & $83.67 \pm 1.22$ & 4.39 & $83.67 \pm 1.22$ & 4.39 & 0.001 & $>0.05$ \\
\hline
\end{tabular}

So, at the beginning of competition period differences are insignificant: in body mass (control group $-94.17 \mathrm{~kg}$ and experimental group - $94.00 \mathrm{~kg} ; \mathrm{P}>0, .05)$; circumference of waist (accordingly $-80.33 \mathrm{~cm}$ and $81.95 \mathrm{~cm}$; $\mathrm{P}>0.05$ ); circumference of hip (accordingly $-79.00 \mathrm{~cm}, 79.72 \mathrm{~cm} ; \mathrm{P}>0.05$ ); circumference of neck (accordingly $-42.50 \mathrm{~cm}$, $42.78 \mathrm{~cm} ; \mathrm{P}>0.05)$; circumference of breast at inhale (accordingly $-113.83 \mathrm{~cm}, 117.88 \mathrm{~cm} ; \mathrm{P}>0.05)$ and circumference of breast at exhale (accordingly $-105.33 \mathrm{~cm}, 107.72 \mathrm{~cm} ; \mathrm{P}>0.05$ ) and shin (accordingly $-40.33 \mathrm{~cm}$, $41.12 \mathrm{~cm} ; \mathrm{P}>0.05)$. 
Variation coefficients of all main anthropological indicators, separately for control and experimental groups, practically did not exceed general initial level. For example for control group it was $\mathrm{V}=11.91 \%$, and for experimental group - $\mathrm{V}=13.30 \%$. Accordingly for control and experimental group variation coefficients were: circumference of hips $\mathrm{V}=6.60 \%, \mathrm{~V}=6,93 \%$; circumference of waist $-\mathrm{V}=8.76 \%, \mathrm{~V}=9.22 \%$; circumference of biceps $-\mathrm{V}=13.32 \%, \mathrm{~V}=$ $10.72 \%$.

Table 4

Mean indicators of reduction of qualified bodybuilders' anthropological data of control and experimental groups at the end of competition period $\left(n_{1}=n_{2}=9\right)$

\begin{tabular}{|l|c|c|c|c|}
\hline \multicolumn{1}{|c|}{ Indicator } & $\mathrm{CG}$ & $\mathrm{EG}$ & \multirow{2}{*}{$\boldsymbol{t}$} & $\boldsymbol{P}$ \\
\cline { 2 - 5 } & $\overline{\mathbf{X}}_{\mathbf{1}} \pm \mathbf{m}_{\mathbf{1}}$ & $\overline{\mathbf{X}}_{\mathbf{2}} \pm \mathbf{m}_{\mathbf{2}}$ & & \\
\hline Body mass, $\mathrm{kg}$ & $11.7 \pm 1.0$ & $5.0 \pm 0.3$ & 5.42 & $<0.01$ \\
\hline Circumference of neck, cm & $4.0 \pm 0.4$ & $2.0 \pm 0.2$ & 3.87 & $<0.01$ \\
\hline Circumference of breast (inhale), cm & $5.2 \pm 0.4$ & $2.2 \pm 0.3$ & 4.81 & $<0.01$ \\
\hline Circumference of breast (exhale), cm & $5.2 \pm 0.4$ & $2.5 \pm 0.2$ & 5.05 & $<0.01$ \\
\hline Circumference of biceps, cm & $3.3 \pm 0.5$ & $1.8 \pm 0.3$ & 2.18 & $>0.05$ \\
\hline Circumference of waist, cm & $4.8 \pm 0.4$ & $2.7 \pm 0.2$ & 4.15 & $<0.01$ \\
\hline Circumference of hip, cm & $4.3 \pm 0.3$ & $2.5 \pm 0.2$ & 3.84 & $<0.01$ \\
\hline Circumference of shin, cm & $2.5 \pm 0.2$ & $1.5 \pm 0.2$ & 3.16 & $<0.05$ \\
\hline Circumference of forearm, cm & $0.2 \pm 0.1$ & $0.8 \pm 0.3$ & 1.60 & $>0.05$ \\
\hline Length of body, cm & $168.0 \pm 1.4$ & $170.5 \pm 1.4$ & 0.77 & $>0.05$ \\
\hline Length of torso, cm & $77.8 \pm 0.6$ & $78.0 \pm 0.6$ & 0.15 & $>0.05$ \\
\hline Length of lower limb, cm & $90.2 \pm 0.9$ & $90.3 \pm 0.9$ & 0.10 & $>0.05$ \\
\hline Length of upper limb, cm & $83.7 \pm 1.2$ & $83.6 \pm 1.2$ & 0.0001 & $>0.05$ \\
\hline
\end{tabular}

For example, at the end of competition period probability of differences was proved: in body mass (control group - $11.7 \mathrm{~kg}$ and experimental group $-5.0 \mathrm{~kg}$; $\mathrm{P}<0.01$ ); circumference of waist (accordingly $-4.8 \mathrm{~cm}, 2.7 \mathrm{~cm} ; \mathrm{P}$ $<0.01$ ); circumference of hip (accordingly $-2.5 \mathrm{~cm}, 1.5 \mathrm{~cm} ; \mathrm{P}<0.05$ ); circumference of neck (accordingly $-4.0 \mathrm{~cm}, 2.0$ $\mathrm{cm} ; \mathrm{P}<0.01$ ); circumference of breast ant inhale (accordingly $-5.2 \mathrm{~cm}, 2.2 \mathrm{~cm} ; \mathrm{P}<0.01$ ) and exhale (accordingly -2.5 $\mathrm{cm}, 1.5 \mathrm{~cm} ; \mathrm{P}<0.05)$.

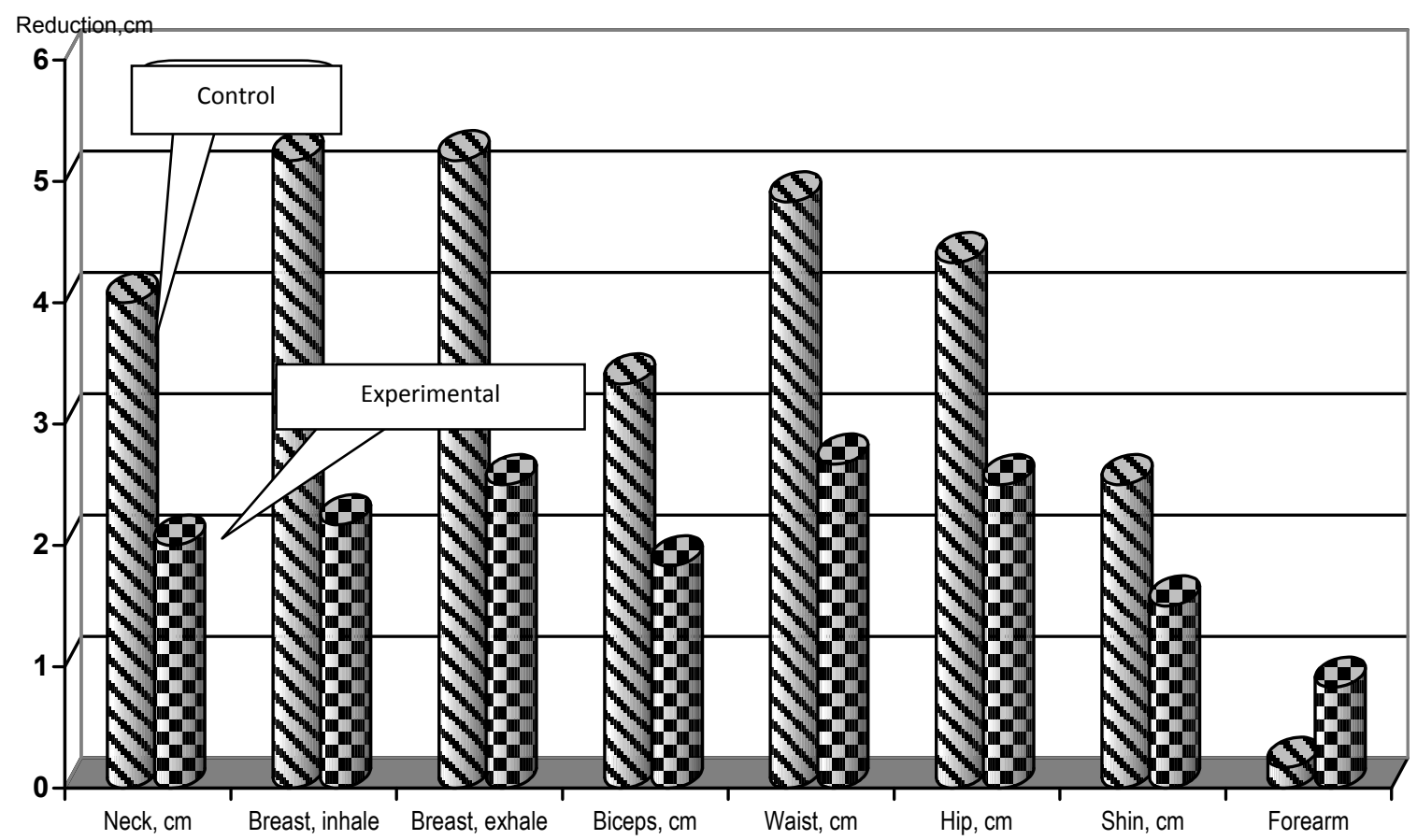

Fig.1. Comparative diagram of increment of anthropometric data of qualified bodybuilders (control and experimental groups) on competition period

\section{Conclusions:}

Thus, perfection of training process for qualified bodybuilders, permits to consider that in EG effect was more expressed and level of fitness can be estimated as optimal. Dynamic of load in this group significantly reduces probability of functional disorders (over-tension, over-training, traumas); it permits to achieve required level of sport fitness without over-tension of adaptation-compensatory mechanisms. In respect to construction of training process, in 
EG methodic of training more facilitates fulfillment of the set task - preservation of muscular mass during burning of subcutaneous fat and water; indicators of body mass are $(\mathrm{t}=5.42 ; \mathrm{p}<0.001)$, Circumference of breast (inhale) $\mathrm{t}=4.81$; $\mathrm{p}<0.001)$ and at exhale $(\mathrm{t}=5.05 ; \mathrm{p}<0.001)$, waist $(\mathrm{t}=4.15 ; \mathrm{p}<0.001)$, hip $(\mathrm{t}=3.84 ; \mathrm{P}<0.01)$ and shin $(\mathrm{t}=3.16 ; \mathrm{p}$ $<0.05)$.

Improved methodic of training for qualified bodybuilders in competition period can be recommended for training of sportsmen with observation of sport and medical requirements, for ensuring of effective and qualitative recreation in transitive period.

Further researches shall include working out and foundation of training process of qualified bodybuilders in transitive period.

\section{References:}

1. Blauberg I. V., Iudin E. G. Stanovlenie i sushchnost' sistemnogo podkhoda [Formtion and essence of system approach]. Moscow, Science, 1973, 272 p. (in Russian)

2. Grishina Iu. I. Osnovy silovoj podgotovki [Basic strength training]. Rostov on Don, Phoenix, 2011 , 280 p. (in Russian)

3. Dzhim V. Iu. Osoblivosti kharchuvannia bodibilderiv u pidgotovchomu periodi trenuvan' [Features nutrition bodybuilders in the preparatory period of training] Slobozhans'kij naukovo-sportivnij visnik. 2013, no. 4(37), pp. 15-19. (in Ukrainian)

4. Dvorkin L. S. Vazhka atletika $i$ vik [Weightlifting and age]. Sverdlovsk, Ural University Publ., 1989,2000 p. (in Ukrainian)

5. Shejko B. I. Pauerlifting [Powerlifting]. Moscow, Sports service, 2003, 532 p. (in Russian)

6. Oleshko V. G. Silovye vidy sporta [Strength kinds of sports]. Kiev, Olympic Literature, 1999, 287 p. (in Russian)

7. Platonov V.N. Sistema podgotovki sportsmenov v olimpijskom sporte [The system of preparation of sportsmen in Olympic sport], Kiev, Olympic Literature, 2004, 808 p. (in Russian)

8. Stecenko A. I. Pauerlifting [Powerlifting]. Cherkasy, NDITEHIMu, 2008, 459 p. (in Ukrainian)

9. Kamaiev O. I., Bezkorovajnij D. O. Rozvitok silovikh zdibnostej 13-15-richnikh iunakiv u silovikh vidakh sportu [Development of power abilities of 13-15-year-old boys in the power types of sport]. Kharkov, KSAPC, 2014, 106 p. (in Ukrainian)

10. Usychenko V. V. Periodizaciia godichnogo cikla podgotovki sportsmenov specializiruiushchikhsia v bodibildinge [Periodization of the annual cycle of training athletes specializing in bodybuilding]. Pedagogics, psychology, medical-biological problems of physical training and sports. 2006, no.7, pp. 123-125. (in Russian).

11. Zverev V. D. Planirovanie trenirovochnoj nagruzki v podgotovitel'nom periode v bodibildinge s uchetom silovoj napravlennosti [Planning the training load in the preparatory period in bodybuilding, taking into account power orientation]. Sankt Petersburg, SPbGAFK P.F. Lesgaft, 200355 p. (in Russian)

12. Dzho Uajder. Sistema stroitel'stva tela [The system of construction of the body]. Moscow, Physical Culture and Sport, 1991, 112 p. (in Russian)

13. Vejder B., Vejder D. Klassicheskij bodibilding [Classic bodybuilding]. Moscow, Exmo, 2003, 432 p. (in Russian)

14. Konnors E., Grimkovski P. , Kimber T. , Mak-Kormik M. Bodibilding [Bodibilding]. Moscow, FAIR PRESS, 2000, 174 p. (in Russian)

15. Djim V.Y., Comparative analysis of exercise equipment jerk in weightlifting and weight sport. Pedagogics, psychology, medical-biological problems of physical training and sports, 2013, no.11, pp. 10-16. http://dx.doi.org/10.6084/m9.figshare.815868

16. Kleiner S. M., Bazzarre T. L., Ainsworth B. E. Nutrional status of nationally ranked elite bodybuilders. International Journal of Sport Nutrition. 1994, no.4, pp. 54-69.

17. Cornelius A. E., Brewer B. W., Van Raalte J.L. Applications of multilevel modeling in sport injury rehabilitation research. International Journal of Sport and Exercise Psychology.2007, vol.5, no.4, pp. $387-405$. http://dx.doi.org/10.1080/1612197X.2007.9671843.

18. Visek A. J., Watson J. C., Hurst J. R., Maxwell J. P., Harris B. S. Athletic identity and aggressiveness: A crosscultural analysis of the athletic identity maintenance model. International Journal of Sport and Exercise Psychology. 2010, vol.8, no.2, pp. 99-116. http://dx.doi.org/10.1080/1612 197X.2010.9671936. 
Information about the author:

Dzhym V.Yu.: http://orcid.org/0000-0002-4869-4844; djimvictor@mail. ru; Kharkov State Academy of Physical Culture; Klochkovskaya str. 99 Kharkov, 61022, Ukraine.

Cite this article as: Dzhym V. Yu. Peculiarities of perfection of training process of the qualified bodybuilder in the competitive period. Physical education of students, 2015, no.1, pp. 11-16. http:// dx.doi.org/10.15561/20755279.2015.0102

The electronic version of this article is the complete one and can be found online at: http://www.sportpedu.org.ua/html/arhive-e.html

This is an Open Access article distributed under the terms of the Creative Commons Attribution License, which permits unrestricted use, distribution, and reproduction in any medium, provided the original work is properly cited (http:// creativecommons.org/licenses/by/3.0/deed.en).

Received: 20.11 .2014

Accepted: 10.12.2014; Published: 30.12.2014 